\title{
Unanticipated Insights into Biomedicine from the Study of Acupuncture
}

\author{
Hugh MacPherson, PhD, ${ }^{1}$ Richard Hammerschlag, PhD, ${ }^{2,3}$ Remy R. Coeytaux, MD, PhD, ${ }^{4,5}$ \\ Robert T. Davis, MS, Richard E. Harris, PhD, Jiang-Ti Kong, MD, Helene M. Langevin, MD, \\ Lixing Lao, PhD, ${ }^{10,11}$ Ryan J. Milley, MAcOM, Vitaly Napadow, PhD, ${ }^{12-14}$ Rosa N. Schnyer, DAOM, ${ }^{15}$ \\ Elisabet Stener-Victorin, PhD, ${ }^{16}$ Claudia M. Witt, MD, MBA, ${ }^{17}$ and Peter M. Wayne, $\mathrm{PhD}^{9}$
}

\begin{abstract}
Research into acupuncture has had ripple effects beyond the field of acupuncture. This paper identifies five exemplars to illustrate that there is tangible evidence of the way insights gleaned from acupuncture research have informed biomedical research, practice, or policy. The first exemplar documents how early research into acupuncture analgesia has expanded into neuroimaging research, broadening physiologic understanding and treatment of chronic pain. The second describes how the acupuncture needle has become a tool to enhance biomedical knowledge of connective tissue. The third exemplar, which illustrates use of a modified acupuncture needle as a sham device, focuses on emergent understanding of placebo effects and, in turn, on insights into therapeutic encounters in treatments unrelated to acupuncture. The fourth exemplar documents that two medical devices now in widespread use were inspired by acupuncture: transcutaneous electrical nerve stimulators for pain control and antinausea wrist bands. The final exemplar describes how pragmatic clinical trial designs applied in acupuncture research have informed current general interest in comparative effectiveness research. In conclusion, these exemplars of unanticipated outcomes of acupuncture research comprise an additional rationale for continued support of basic and clinical research evaluating acupuncture and other under-researched therapies.
\end{abstract}

\section{Background}

W ITHIN THE HISTORY OF MEDICINE, there are examples of scientific discoveries that emerged from unrelated or marginally related research. Such events often result from cross-fertilization of ideas, as for example when the emergent concept of autoimmunity catalyzed the shift in understanding of type 1 diabetes from a genetically determined endocrine imbalance to an organ-specific autoimmune disorder. ${ }^{1} \mathrm{New}$ ideas also arise when research efforts to target specific questions reveal unexpected findings, for example, the effectiveness of sildenafil for treating erectile dysfunction

\footnotetext{
${ }^{1}$ Department of Health Sciences, University of York, York, United Kingdom.

${ }^{2}$ Research Department, Oregon College of Oriental Medicine, Portland, OR.

${ }^{3}$ The Institute for Integrative Health, Baltimore, MD.

${ }^{4}$ Duke Clinical Research Institute, Durham, NC.

${ }^{5}$ Department of Community and Family Medicine, Duke University, Durham, NC.

${ }^{6}$ Stromatec, Inc., Burlington, VT.

${ }^{7}$ Department of Anesthesiology, University of Michigan, Ann Arbor, MI.

${ }^{8}$ Department of Anesthesiology, Perioperative and Pain Medicine, Stanford University School of Medicine, Stanford, CA.

${ }^{9}$ Osher Center for Integrative Medicine, Brigham and Women's Hospital and Harvard Medical School, Boston, MA.

${ }^{10}$ School of Chinese Medicine, The University of Hong Kong, Hong Kong.

${ }^{11}$ Center for Integrative Medicine, School of Medicine, University of Maryland, Baltimore, MD.

${ }^{12}$ Martinos Center for Biomedical Imaging, Massachusetts General Hospital, Harvard Medical School, Charlestown, MA.

${ }^{13}$ Department of Radiology, Logan University, Chesterfield, MO.

${ }_{15}^{14}$ Department of Biomedical Engineering, Kyunghee University, Yongin, Korea.

${ }^{15}$ School of Nursing, University of Texas, Austin, TX.

${ }^{16}$ Institute of Neuroscience and Physiology, Department of Physiology, Sahlgrenska Academy, University of Gothenburg, Gothenburg, Sweden.

${ }^{17}$ Institute for Complementary and Integrative Medicine, University Hospital Zurich, University of Zurich, Zurich, Switzerland.

(C) Hugh MacPherson, et al. 2016; Published by Mary Ann Liebert, Inc. This Open Access article is distributed under the terms of the Creative Commons Attribution Noncommercial License (http://creativecommons.org/licenses/by-nc/4.0/) which permits any noncommercial use, distribution, and reproduction in any medium, provided the original author(s) and the source are credited.
} 
(observed during its testing for coronary artery disease) and iproniazid, an early treatment for depression (during testing as a chemotherapeutic agent for tuberculosis). ${ }^{2}$ The present paper examines results from acupuncture research that have affected biomedicine.

A major impetus to acupuncture research in the United States occurred in 1998, when the National Center for Complementary and Alternative Medicine (now the National Center for Complementary and Integrative Health) was established within the National Institutes of Health (NIH). This support has led to important research findings regarding acupuncture's effectiveness, ${ }^{3}$ as well as advances in the understanding of acupuncture's mechanisms of action. $^{4}$ Despite this considerable progress, debate remains regarding the interpretation and acceptance of the evidence base for acupuncture and the value of future research. ${ }^{5,6}$ Missing from these reviews and discussions is a consideration of the often unexpected and broad-reaching discoveries that emerge when the traditions of biomedicine and acupuncture meet in the context of objective and systematic scientific exploration.

This paper documents how ripple effects of acupuncture research have traveled beyond the field of acupuncture to affect several aspects of biomedicine. Specifically, acupuncture research has (1) expanded scientific and clinical knowledge in the fields of chronic pain, connective tissue, and placebo effects; (2) spawned the design of novel medical devices, which have increased treatment options in the areas of pain control and nausea suppression; and (3) furthered the development of research methods through the design and implementation of pragmatic clinical trials for chronic pain. Few are aware of the origins and pathways of these developments because they are now sufficiently integrated within the knowledge base and practice of biomedicine. The paper concludes by proposing that these exemplars provide evidence that acupuncture research has broadened biomedical understanding with regard to research, practice, and policy, as well as strengthening the case for continued support of basic and clinical research evaluating acupuncture and other underresearched therapies.

\section{Exemplars}

\section{Acupuncture, endorphins, and analgesia research}

Among the earliest research findings pertinent to both acupuncture and biomedicine are the demonstrations in animal models and humans that acupuncture analgesia is mediated in part by endogenous opioids. ${ }^{7,8}$ These findings, including similar pharmacologic sensitivities of morphine analgesia and acupuncture analgesia and results indicating that different types of "endorphins" are released by different frequencies of electro-acupuncture, generated substantial interest within the biomedical community. Timely reviews appeared in high-profile journals, ${ }^{9,10}$ and the acupuncture/endogenous opioid connection was endorsed at the 1997 NIH Consensus Conference on Acupuncture. ${ }^{11}$

More recently, biomedical research on pain has seen significant contributions from acupuncture neuroimaging research. $^{4,12}$ For example, positron emission tomography detected an increase of mu-opioid receptor-binding potential in multiple brain regions that correlated with acupunctureassociated reduction in fibromyalgia pain. ${ }^{13}$ This specific demonstration of altered brain activity in patients with fibromyalgia has been cited as an important precedent in studies on the pathophysiology of other chronic pain conditions. ${ }^{14,15}$

In a functional magnetic resonance imaging study, patients with carpal tunnel syndrome whose subjective and objective symptoms improved following acupuncture demonstrated a return to normal mapping of their carpal tunnel syndrome-affected digits on the primary somatosensory cortex (S1). ${ }^{16}$ This finding of central nervous system-related peripheral pathology has been referenced in publications on neuroplasticity in carpal tunnel syndrome ${ }^{17,18}$ and neuropathic pain. ${ }^{19}$

Acupuncture neuroimaging research has also identified a novel brain-based marker for clinical pain perception. Patients with fibromyalgia show elevation of an intrinsic brain connectivity marker that correlates significantly with pain intensity $^{20}$ and is normalized following successful acupuncture analgesia therapy. ${ }^{21}$ This research has been cited in several recent reviews for its importance as an objective biological marker for pain neuroimaging research. ${ }^{22-24}$

The translational acupuncture research examples summarized above have contributed to the development of broader clinical guidelines and reimbursement policies related to pain, and to the use of acupuncture as an intervention within mainstream medicine. With an increased public profile and insurance reimbursement, pain is now the leading indication for acupuncture use, as revealed in surveys from the United States ${ }^{25}$ and Europe. ${ }^{26}$ Use has increased in parallel with greater acceptance of acupuncture by physicians and allied specialists. For example, in the United Kingdom about one third of the 4 million annual acupuncture sessions are provided (free at point of delivery) within the National Health Service by biomedical practitioners (doctors and physiotherapists). ${ }^{27}$ In Germany, around 30,000 physicians, some of whom contributed to high-profile randomized controlled trials of acupuncture for chronic pain, ${ }^{28}$ currently provide acupuncture, which is reimbursed by public health insurance. ${ }^{29}$

\section{Connective tissue in health and disease}

Connective tissue has long been the orphan child of medicine. Although it is part of the musculoskeletal system, connective tissue is basically absent from orthopedic and rheumatology textbooks, which are principally concerned with bones, muscles, and cartilage. In current textbooks, the nonspecialized connective tissues forming the fascia that envelop all muscles, nerves bones, and blood vessels are typically allotted a short paragraph, if mentioned at all. Although the consequence of connective tissue injuryscarring and adhesion formation-is well recognized, the secondary effects of these adhesions, in particular their relevance to chronic pain, is little discussed. ${ }^{30}$

However, interest in connective tissue has been growing, and acupuncture research has contributed to this trend within biomedicine. One area that has attracted researchers to this field has been the study of mechanotransduction, or the mechanisms by which cells perceive, interpret, and respond to mechanical forces present in tissues. ${ }^{31}$ Through specialized protein complexes, cells sense outside forces and "transduce" these mechanical signals into cellular responses, such 
as activation/deactivation of signaling molecules, translocation of transcription factors into the nucleus, and changes in gene expression. But current research on mechanotransduction has a well-recognized limitation: Almost all of its knowledge is derived from cultured cells. Extension of this work into whole, live tissue has resulted from studies in which the acupuncture needle provides a method to deliver a precise mechanical signal that can produce dose-dependent responses in areolar connective tissue fibroblasts. ${ }^{32,33}$ Sustained stretching of tissue is inherent to this response and has been shown to cause local purinergic signaling and active, cell-mediated tissue relaxation. ${ }^{34}$ Before experiments with the acupuncture needle, these functions of fibroblasts were unknown. Thus, novel insights gleaned from acupuncturerelated research have led to an improved understanding of basic mechanobiology. ${ }^{31,35-37}$

Acupuncture-related studies on connective tissue also have contributed to a resurgence of interest and greater understanding of connective tissue pathology associated with chronic musculoskeletal pain and fibrotic diseases. ${ }^{38,39}$ The areolar connective tissue layers that wind around the needle and respond to acupuncture needle manipulation are the same layers that normally allow gliding between adjacent layers of fascia during normal movement and become abnormal in musculoskeletal pain. ${ }^{40}$ Recent ultrasound studies have shown that the connective tissues surrounding the muscles of the back are thicker in people with chronic low back pain than in control participants without back pain $^{41}$; similar results have been reported in patients with chronic pelvic pain. ${ }^{42}$

These insights and new avenues of investigation into mechanobiology and connective tissue pathophysiology are not likely to have occurred without the initial research that used acupuncture needles to interact specifically with loose connective tissue.

\section{Toward a better understanding of placebo effects}

Placebo effects, or nonspecific treatment effects, occur in preclinical research, clinical practice, and randomized controlled clinical trials, with large effect sizes in functional disorders such as chronic pain ${ }^{43}$ and depression. ${ }^{44}$ This section highlights how acupuncture research on chronic pain has contributed to the understanding and potential clinical use of placebo effects in biomedicine.

The use of the sham acupuncture needle as a unique placebo device has assisted researchers in identifying key components of treatment that may enhance the effect of placebo. In a seminal study by Kaptchuk et al., patients with irritable bowel syndrome reported increasing symptom relief with escalating "doses" of placebo: observation alone, observation plus sham acupuncture, and observation plus sham acupuncture plus positive patient-provider relationship. ${ }^{45}$ This study has significantly affected the field of gastroenterology, enhancing appreciation of the doctor as a "walking placebo," 46 and highlighting the potential that arises from placebo research for patients with chronic abdominal symptoms. ${ }^{47}$ This specific line of research in irritable bowel syndrome also set the stage for exploring genomic effects on placebo response, ${ }^{48}$ addressing ethical questions related to placebo effects, ${ }^{49}$ the first open-label placebo pill study, ${ }^{50}$ and other novel placebo study research designs. ${ }^{51}$
Acupuncture research has also been credited with identifying serum and genetic biomarkers associated with the placebo response. ${ }^{52}$ These markers include serum osteoprotegerin and tumor necrosis factor-related weak inducer of apoptosis ${ }^{53}$ as well as catecholamine O-methyl transferase functional val158met polymorphism. ${ }^{48}$

In summary, acupuncture research has contributed to the renewed interest in the role of placebo in clinical care and has helped advance placebo research in three major areas: (1) the rate and the degree of response to placebo, which can be high, leading to prolonged symptom (often pain) relief in up to half of the participants ${ }^{52,54}$; (2) the important role of the provider-patient relationship in the therapeutic response to placebo ${ }^{45,55}$; and (3) identification of additional biomarkers associated with placebo response. ${ }^{53,56}$ These innovative findings provide a scientific basis for ethically enhancing the placebo effect in the clinical setting by strengthening the provider-patient relationship (e.g., communications and clear explanation of possible benefits of a treatment ${ }^{46,54}$ ) and by optimizing the therapeutic environment and rituals. ${ }^{49}$

\section{Acupuncture-related devices that have affected biomedicine}

The development of several currently used biomedical devices has clear links to acupuncture-related research. This section highlights two widely used devices: transcutaneous electrical nerve stimulation (TENS) units for analgesia and acupressure bands for relief of nausea.

Acupuncture and TENS. The modern TENS unit as a means of pain relief was developed from a technique of dorsal column electroanalgesia by C. Norman Shealy, MD, in the early 1970s. ${ }^{57,58}$ According to Shealy, "I began stimulating acupuncture needles with electrical energy in the mid 60's. Later, without needles, I introduced TENS.",59 This led to a TENS patent issued to Medtronic in 1974. ${ }^{60}$

In the United States, TENS is a reimbursable medical procedure for pain relief in both private and public insurance sectors. In the private sector, TENS is coded based on the American Medical Association (AMA) Current Procedural Terminology (CPT 97014 or 64550) and in the public sector based on the AMA's Healthcare Common Procedure Coding System (HCPCS- G0283). ${ }^{61}$ The effect of TENS on the medical field at large is also reflected in U.S.-based insurance guidelines; for example, Blue Cross-Blue Shield Association currently supports the use of this device for chronic spinal pain (neck or back). ${ }^{62}$ TENS devices have received U.S. Food and Drug Administration (FDA) approval for both pain relief and the prevention of pain. ${ }^{63}$

Acupuncture and acupressure bands. Numerous acupressure devices (e.g., Sea-Band ${ }^{\circledR}$, Sea-Band Ltd., Leicestershire, United Kingdom) are available on the open market, most often sold as a means to relieve nausea and vomiting. The history of these devices is inseparably linked to the clinical practice of acupuncture and acupressure, with clinical research reinforcing their acceptance. The earliest research trials were initiated in Ireland by J.W. Dundee, who had observed physicians in China teaching patients to press on acupuncture point PC6, located on the inner wrist. ${ }^{64}$ 
Dundee and colleagues were among the first to conduct randomized controlled trials to demonstrate the antiemetic effectiveness of acupuncture, ${ }^{65}$ a finding replicated with manual acupressure using a wristband device. ${ }^{66}$ Numerous subsequent acupuncture and acupressure trials have been evaluated in systematic reviews of nausea and emesis associated with postoperative recovery ${ }^{67}$ and chemotherapy. ${ }^{68}$

The 1997 NIH Consensus Conference on Acupuncture reported promising results from stimulation of PC6 for postoperative and chemotherapy-related nausea and vomiting. ${ }^{11}$ Several PC6 acupressure stimulation devices have received FDA approval for nausea control and are now available on the open market. ${ }^{69}$

The common use of these acupressure devices, combined with clinical research results, has translated into several international clinical guidelines within biomedicine recommending acupressure. Such guidelines include those of the Society of Obstetrics \& Gynecology of Canada on the management of nausea and vomiting in pregnancy, ${ }^{70}$ the U.S. Agency for Healthcare Research and Quality, ${ }^{71}$ and the United Kingdom's National Institute for Health and Care Excellence (NICE). ${ }^{72,73}$

\section{Pragmatic clinical trials}

The evolution of clinical research in biomedicine toward more pragmatic randomized controlled trials, a method often encouraged in comparative effectiveness research, ${ }^{74}$ was informed by earlier research involving pragmatic trials of acupuncture for chronic pain conditions in the United Kingdom with recruitment starting in $1999^{75,76}$ and in Germany starting in $2001 .^{28}$ The need for a more pragmatic approach was supported in 2003 by Tunis and colleagues, ${ }^{77}$ who argued that there was a paucity of published research designed to directly answer questions faced by policymakers, clinicians, and patients. Most trials, they observed, used efficacy or explanatory designs that evaluated the degree to which a specific component of an intervention can outperform a placebo or sham procedure. Their recommendations to increase the value of clinical research for decision-making in health policy and practice included placing a higher priority on pragmatic (practical) clinical trials.

The York Acupuncture for Back Pain trial provides an example of how a pragmatic acupuncture trial has been influential beyond the field of acupuncture research. The trial, in which 241 patients received a short course of up to 10 acupuncture sessions plus usual care or usual care alone, provided evidence that acupuncture is both clinically effective and cost-effective at 24 months after randomization. ${ }^{75}$ This study was cited as the exemplar of a "highly pragmatic" trial in the Consolidated Standards of Reporting Trials statement extension for pragmatic trials, published in $2008 .^{78}$

Since 2009, comparative effectiveness research, which compares at least two interventions, each with the potential to be "best practice," has been promoted by the U.S.-based Institute of Medicine, much along the same lines as the United Kingdom and German trials, with a focus on assisting consumers, clinicians, purchasers, and policymakers to make informed decisions that will improve healthcare at both the individual and population levels. ${ }^{74}$ To this end, pragmatic trials are featured by the Institute of Medicine as one of the most important research methods within comparative effectiveness research. The recently created Patient-Centered Outcomes Research Institute, which directly supports large pragmatic trials to evaluate patient-centered outcomes, ${ }^{79}$ reflects the expanding interest in pragmatic trials.

The United Kingdom pragmatic trials of acupuncture for back pain ${ }^{75}$ and for chronic headache and migraine ${ }^{76}$ both demonstrated clear evidence of cost-effectiveness as well as clinical effectiveness. ${ }^{80,81}$ As a result, these trials contributed to a major shift in health policy within biomedicine. Both were cited by NICE as providing key evidence for the NICE recommendations that acupuncture should be offered within the National Health Service as an option for both persistent low back pain ${ }^{82}$ and headache/migraine. ${ }^{83}$ The findings of the German acupuncture trials ${ }^{28}$ contributed to a 2006 decision by that country's health authorities in favor of insurance-based reimbursement to physicians providing acupuncture for osteoarthritis of the knee and chronic low back pain. ${ }^{29}$

\section{Discussion}

To the authors' knowledge, this is the first attempt to consider the effect of acupuncture research beyond the field of acupuncture itself, in particular its effect on research, practice, and healthcare policy within contemporary biomedicine. This article sought not only to identify the clearest examples of this scientific cross-fertilization but also to present a variety of topic areas not limited to different conditions for which acupuncture efficacy or effectiveness has been assessed. Thus, while this article described the effect of acupuncture research on biomedical understanding of chronic pain conditions and on the emerging role of connective tissue, it also documented clear instances of effects in the disparate areas of medical devices, placebo effects, and research methods.

Central to this paper is the question of how to define and recognize "effect." An initial realization was that the varied nature of the included topics would preclude an across-theboard application of a single criterion. Nevertheless, the consensus position was to seek tangible indications that information gleaned from acupuncture research had broadened the biomedical framework in regard to research, practice, or policy. Following this guideline, this article described, for example, how research on connective tissue has been advanced by use of the acupuncture needle as a probe in intact tissue. In the realm of practice and policy, we described two acupuncture-related devices that have received FDA approval as effective treatment options within mainstream medicine.

Similar findings of significant insights have been reported in other areas of research, especially in the scientific evaluation of poorly understood phenomena. Promise of novel "spin-offs" was a key argument underlying funding and investment in the NIH Office of Rare Diseases. ${ }^{84}$ As an example, the Wyss Institute for Biologically Inspired Engineering, on the Harvard Medical School campus, has consciously fostered cross-disciplinary research by assembling a diverse faculty that "uses Nature's design principles to develop bio-inspired materials and devices that will transform medicine and create a more sustainable world." 85 Similarly, the Media Lab on the Massachusetts Institute of 
Technology campus actively promotes an "antidisciplinary culture, encouraging the mixing and matching of seemingly disparate research areas" to create "disruptive technologies." 86 In light of such institutional efforts to foster "silo-busting" research, conscious efforts to engender unanticipated insights should be considered as future research investment strategies for acupuncture and other under-researched therapies.

This review has limitations. It is a narrative one based on exemplars rather than a systematic review or an exhaustive presentation on all such instances of acupuncture influencing biomedicine. The authors are potentially influenced by their own research and clinical expertise. Additionally, this article has not explicitly explored the many ways that biomedicine has influenced acupuncture.

\section{Acknowledgments}

The authors acknowledge Laura Triplett for administrative support.

\section{Author Disclosure Statement}

No competing financial interests exist.

\section{References}

1. Gale EAM. The discovery of type 1 diabetes. Diabetes 2001;50:217-226.

2. Ban TA. The role of serendipity in drug discovery. Dialogues Clin Neurosci. 2006;8:335-344.

3. Vickers AJ, Cronin AM, Maschino AC, et al. Acupuncture for chronic pain: individual patient data meta-analysis. Arch Intern Med 2012;172:1444-1453.

4. Napadow V, Webb JM, Pearson N, Hammerschlag R. Neurobiological correlates of acupuncture: November 1718, 2005. J Altern Complement Med. 2006;12:931-935.

5. Colquhoun D, Novella SP. Acupuncture is theatrical placebo. Anesth Analg 2013;116:1360-1363.

6. Wang S-M, Harris RE, Lin Y-C, Gan T-J. Acupuncture in 21st century anesthesia: is there a needle in the haystack? Anesth Analg 2013;116:1356-1359.

7. Han JS. Acupuncture and endorphins. Neurosci Lett 2004; 361:258-261.

8. Pomeranz B. Scientific research into acupuncture for the relief of pain. J Altern Complement Med 1996;2:53-60.

9. Fields HL. Pain II: new approaches to management. Ann Neurol 1981;9:101-106.

10. Ulett GA. Acupuncture treatments for pain relief. JAMA 1981;245:768-769.

11. National Institutes of Health. Consensus Conference. Acupuncture. JAMA 1998;280:1518-1524.

12. Dhond RP, Kettner N, Napadow V. Neuroimaging acupuncture effects in the human brain. J Altern Complement Med 2007;13:603-616.

13. Harris RE, Zubieta JK, Scott DJ, Napadow V, Gracely RH, Clauw DJ. Traditional Chinese acupuncture and placebo (sham) acupuncture are differentiated by their effects on ++opioid receptors (MORs). Neuroimage 2009;47:1077-1085.

14. Martikainen IK, Peciña M, Love TM, et al. Alterations in endogenous opioid functional measures in chronic back pain. J Neurosci 2013;33:14729-14737.

15. DosSantos MF, Martikainen IK, Nascimento TD, et al. Reduced basal ganglia mu-opioid receptor availability in trigeminal neuropathic pain: a pilot study. Mol Pain 2012;8:74.
16. Napadow V, Liu J, Li M, et al. Somatosensory cortical plasticity in carpal tunnel syndrome treated by acupuncture. Hum Brain Mapp 2007;28:159-171.

17. Nataraj R, Evans PJ, Seitz WH, Li Z-M. Effects of carpal tunnel syndrome on reach-to-pinch performance. PLoS One 2014;9:e92063.

18. Zhang W, Johnston JA, Ross MA, et al. Effects of carpal tunnel syndrome on dexterous manipulation are grip typedependent. PLoS One 2013;8:e53751.

19. Schwenkreis P, Scherens A, Rönnau A-K, Höffken O, Tegenthoff M, Maier C. Cortical disinhibition occurs in chronic neuropathic, but not in chronic nociceptive pain. BMC Neurosci 2010;11:73.

20. Napadow V, LaCount L, Park K, As-Sanie S, Clauw DJ, Harris RE. Intrinsic brain connectivity in fibromyalgia is associated with chronic pain intensity. Arthritis Rheum 2010;62:2545-2555.

21. Napadow V, Kim J, Clauw DJ, Harris RE. Decreased intrinsic brain connectivity is associated with reduced clinical pain in fibromyalgia. Arthritis Rheum 2012;64:2398-2403.

22. Lee MC, Tracey I. Imaging pain: a potent means for investigating pain mechanisms in patients. $\mathrm{Br} \mathrm{J}$ Anaesth 2013;111:64-72.

23. Gerdle B, Ghafouri B, Ernberg M, Larsson B. Chronic musculoskeletal pain: review of mechanisms and biochemical biomarkers as assessed by the microdialysis technique. J Pain Res 2014;7:313-326.

24. Wiech K, Tracey I. Pain, decisions, and actions: a motivational perspective. Front Neurosci 2013;7:46.

25. Barnes PM, Bloom B, Nahin RL. Complementary and alternative medicine use among adults and children: United States, 2007. Natl Health Stat Report 2008;(12):1-23.

26. Robinson N, Lorenc A, Ding W, Jia J, Bovey M, Wang $\mathrm{XM}$. Exploring practice characteristics and research priorities of practitioners of traditional acupuncture in China and the EU-A survey. J Ethnopharmacol. 2012;140:604-613.

27. Hopton AK, Curnoe S, Kanaan M, MacPherson H. Acupuncture in practice: mapping the providers, the patients and the settings in a national cross-sectional survey. BMJ Open 2012;2:e000456.

28. Cummings M. Modellvorhaben Akupunktur-a summary of the ART, ARC and GERAC trials. Acupunct Med 2009; 27:26-30.

29. Federal Joint Committee (Germany). Tragende Gründe zum Beschluss des Gemeinsamen Bundesausschusses zur Akupunktur. Federal Joint Committee (Germany). Apr 2006. Online document at: https://www.g-ba.de/downloads/ 40-268-71/2006-04-18_Akupunktur-TGr.pdf, accessed January 4, 2016.

30. Langevin HM. What role does fascia play in rheumatic diseases? Rheumatologist. March 1, 2014. Online document at: http://www.the-rheumatologist.org/article/what-role-doesfascia-play-in-rheumatic-diseases/, accessed January 4, 2016.

31. Jahed Z, Shams H, Mehrbod M, Mofrad MRK. Mechanotransduction pathways linking the extracellular matrix to the nucleus. Int Rev Cell Mol Biol 2014;310:171-220.

32. Langevin HM, Bouffard NA, Badger GJ, Iatridis JC, Howe AK. Dynamic fibroblast cytoskeletal response to subcutaneous tissue stretch ex vivo and in vivo. Am J Physiol Cell Physiol. 2005;288:C747-756.

33. Langevin HM, Bouffard NA, Churchill DL, Badger GJ. Connective tissue fibroblast response to acupuncture: dosedependent effect of bidirectional needle rotation. J Altern Complement Med 2007;13:355-360. 
34. Langevin HM, Fujita T, Bouffard NA, et al. Fibroblast cytoskeletal remodeling induced by tissue stretch involves ATP signaling. J Cell Physiol. 2013;228:1922-1926.

35. Ingber DE. Mechanobiology and diseases of mechanotransduction. Ann Med 2003;35:564-577.

36. Lammerding J. Mechanics of the nucleus. Compr Physiol 2011;1:783-807.

37. Van Gerwen DJ, Dankelman J, van den Dobbelsteen JJ. Needle-tissue interaction forces-a survey of experimental data. Med Eng Phys. 2012;34:665-680.

38. Traverso S. Mechanical signalling in tissues and its possible role in nociception. Theoret Biol Forum. 2011;104:75-84.

39. Benjamin M. The fascia of the limbs and back-a review. J Anat 2009;214:1-18.

40. Langevin HM, Fox JR, Koptiuch C, et al. Reduced thoracolumbar fascia shear strain in human chronic low back pain. BMC Musculoskelet Disord. 2011;12:203.

41. Langevin HM, Stevens-Tuttle D, Fox JR, et al. Ultrasound evidence of altered lumbar connective tissue structure in human subjects with chronic low back pain. BMC Musculoskelet Disord 2009;10:151.

42. Whittaker JL, Warner MB, Stokes M. Comparison of the sonographic features of the abdominal wall muscles and connective tissues in individuals with and without lumbopelvic pain. J Orthop Sports Phys Ther 2013;43:11-19.

43. Dworkin RH, Turk DC, Peirce-Sandner S, et al. Considerations for improving assay sensitivity in chronic pain clinical trials: IMMPACT recommendations. Pain 2012; 153:1148-1158.

44. Khan A, Schwartz K. Study designs and outcomes in antidepressant clinical trials. Essent Psychopharmacol 2005; 6:221-226.

45. Kaptchuk TJ, Kelley JM, Conboy LA, et al. Components of placebo effect: randomised controlled trial in patients with irritable bowel syndrome. BMJ 2008;336:999-1003.

46. Jubb J, Bensing JM. The sweetest pill to swallow: how patient neurobiology can be harnessed to maximise placebo effects. Neurosci Biobehav Rev 2013;37:2709-2720.

47. Schmid J, Langhorst J, Gaß F, et al. Placebo analgesia in patients with functional and organic abdominal pain: a fMRI study in IBS, UC and healthy volunteers. Gut 2015;64:418-427.

48. Hall KT, Kaptchuk TJ. Genetic biomarkers of placebo response: what could it mean for future trial design? Clin Investig (Lond). 2013;3:311-314.

49. Finniss DG, Kaptchuk TJ, Miller F, Benedetti F. Biological, clinical, and ethical advances of placebo effects. Lancet 2010;375:686-695.

50. Kaptchuk TJ, Friedlander E, Kelley JM, et al. Placebos without deception: a randomized controlled trial in irritable bowel syndrome. PloS One 2010;5:e15591.

51. Wechsler ME, Kelley JM, Boyd IOE, et al. Active albuterol or placebo, sham acupuncture, or no intervention in asthma. N Engl J Med 2011;365:119-126.

52. Benedetti F, Frisaldi E. Creating placebo responders and nonresponders in the laboratory: boons and banes. Pain Manag 2014;4:165-167.

53. Kokkotou E, Conboy LA, Ziogas DC, et al. Serum correlates of the placebo effect in irritable bowel syndrome. Neurogastroenterol Motil 2010;22:285-281.

54. Klinger R, Colloca L, Bingel U, Flor H. Placebo analgesia: clinical applications. Pain 2014;155:1055-1058.

55. Kelley JM, Lembo AJ, Ablon JS, et al. Patient and practitioner influences on the placebo effect in irritable bowel syndrome. Psychosom Med 2009;71):789-797.
56. Hall KT, Lembo AJ, Kirsch I, et al. Catechol-Omethyltransferase val158met polymorphism predicts placebo effect in irritable bowel syndrome. PLoS One 2012;7: e48135.

57. Shealy CN, Mortimer JT, Hagfors NR. Dorsal column electroanalgesia. J Neurosurg 1970;32:560-564.

58. Shealy CN. Transcutaneous electrical stimulation for control of pain. Clin Neurosurg 1974;21:269-277.

59. Shealy CN. Shealy wellness. September 29, 2014. Online document at: www.normshealy.com/the-sacred-rings/, accessed January 4, 2016.

60. Maurer D. Transcutaneous stimulator and stimulation method. US patent 36733979. 1974.

61. Abraham M, American Medical Association. CPT 2014: Current Procedural Terminology. Chicago: American Medical Association, 2015.

62. Blue Cross-Blue Shield Association. Transcutaneous electrical nerve stimulator (TENS). June 1, 2015. Online document at: www.bcbsms.com/com/bcbsms/apps/PolicySearch/ views/ViewPolicy.php?\&noprint=yes\&path=/policy/emed/ Transcutaneous_Elec_Nerve_Stim_(TENS).html, accessed January 4, 2016.

63. U.S. Food and Drug Administration. FDA Center for Devices and Radiological Health. Guidance documents - draft guidance for industry and FDA staff: Class II special controls guidance document: transcutaneous electrical nerve stimulator for pain relief intended. September 30, 2014. Online document at: www.fda.gov/MedicalDevices/DeviceRegulation andGuidance/GuidanceDocuments/ucm198645.htm, accessed June 22, 2015.

64. Dundee JW, Chestnutt WN, Ghaly RG, Lynas AG. Traditional Chinese acupuncture: a potentially useful antiemetic? Br Med J (Clin Res Ed) 1986;293:583-584.

65. Dundee JW. Belfast experience with P6 acupuncture antiemesis. Ulster Med J 1990;59:63-70.

66. Hyde E. Acupressure therapy for morning sickness. A controlled clinical trial. J Nurse Midwifery 1989;34: 171-178.

67. Lee A, Fan LT. Stimulation of the wrist acupuncture point P6 for preventing postoperative nausea and vomiting. Cochrane Database Syst Rev 2009;CD003281.

68. Ezzo JM, Richardson MA, Vickers A, et al. Acupuncturepoint stimulation for chemotherapy-induced nausea or vomiting. Cochrane Database Syst Rev 2006;:CD002285.

69. U.S. Food and Drug Administration. FDA approved devices: AcuBand. June 1, 2015. Online document at: www .accessdata.fda.gov/cdrh_docs/pdf5/K053509.pdf, accessed January 4, 2016.

70. Arsenault M-Y, Lane CA, MacKinnon CJ, et al. The management of nausea and vomiting of pregnancy. J Obstet Gynaecol Can. 2002;24:817-831.

71. National Guideline Clearinghouse. Putting evidence into practice: evidence-based interventions to prevent, manage, and treat chemotherapy-induced nausea and vomiting. 2007. Online document at: www.guideline.gov/content .aspx $? \mathrm{id}=15701 \&$ search $=$ nausea $\% 2 \mathrm{c}+$ acupressure, accessed January 4, 2016.

72. National Institute for Health and Clinical Excellence. Antenatal care. Routine care for the healthy pregnant woman. London: National Institute for Health and Clinical Excellence, 2008.

73. National Institute for Health and Clinical Excellence. Caesarean section. London: National Institute for Health and Clinical Excellence, 2012:1-58. 
74. Institute of Medicine. Initial National Priorities for Comparative Effectiveness Research. Washington, DC: National Academies Press, 2009.

75. Thomas KJ, MacPherson H, Thorpe L, et al. Randomised controlled trial of a short course of traditional acupuncture compared with usual care for persistent non-specific low back pain. BMJ. 2006;333:623-626.

76. Vickers AJ, Rees RW, Zollman CE, et al. Acupuncture for chronic headache in primary care: large, pragmatic, randomised trial. BMJ 2004;328:744.

77. Tunis SR, Stryer DB, Clancy CM. Practical clinical trials: increasing the value of clinical research for decision making in clinical and health policy. JAMA 2003;290:1624-1632.

78. Zwarenstein M, Treweek S, Gagnier JJ, et al. Improving the reporting of pragmatic trials: an extension of the CONSORT statement. BMJ 2008;337:1-8.

79. Patient-Centered Outcomes Research Institute (PCORI). PCORI funding announcement: large pragmatic studies to evaluate patient-centered outcomes. June 12, 2014. Online document at: www.pcori.org/funding-opportunities/fundingannouncements/large-pragmatic-studies-to-evaluate-patientcentered-outcomes-fall-2014-cycle/, accessed January 4, 2016.

80. Ratcliffe J, Thomas KJ, MacPherson H, Brazier J. A randomised controlled trial of acupuncture care for persistent low back pain: cost effectiveness analysis. BMJ. 2006;333: $626-628$.
81. Wonderling D, Vickers AJ, Grieve R, McCarney R. Cost effectiveness analysis of a randomised trial of acupuncture for chronic headache in primary care. BMJ. 2004;328:747.

82. National Institute for Health and Care Excellence. Low back pain:eEarly management of persistent non-specific low back pain [Internet]. London: National Institute for Health and Care Excellence; 2009.

83. National Institute for Health and Care Excellence. Headaches: diagnosis and management of headaches in young people and adults (CG150). London: National Institute for Health and Care Excellence, 2012.

84. Hampton T. Rare disease research gets boost. JAMA. 2006;295:2836-2838.

85. Wyss Institute. Online document at: http://wyss.harvard .edu/viewpage/about-us/about, accessed January 4, 2016.

86. MIT Media Lab. Online document at: https://www.media .mit.edu/about, accessed January 4, 2016.

$$
\begin{array}{r}
\text { Address correspondence to: } \\
\text { Hugh MacPherson, PhD } \\
\text { Department of Health Sciences } \\
\text { University of York } \\
\text { Heslington, York YO10 5DD } \\
\text { United Kingdom }
\end{array}
$$

E-mail: hugh.macpherson@york.ac.uk 